\title{
Attitudes about Brain-Computer Interface (BCI) technology among Spanish rehabilitation professionals
}

\author{
Aníbal Monasterio Astobiza ${ }^{1,2}$ - David Rodriguez Arias-Vailhen ${ }^{3} \cdot$ Txetxu Ausín $^{4} \cdot$ Mario Toboso $^{4} \cdot$ Manuel Aparicio $^{5}$. \\ Daniel López ${ }^{4}$
}

Received: 16 February 2021 / Accepted: 22 September 2021 / Published online: 17 October 2021

(c) The Author(s) 2021

\begin{abstract}
To assess - from a qualitative perspective - the perceptions and attitudes of Spanish rehabilitation professionals (e.g. rehabilitation doctors, speech therapists, physical therapists) about Brain-Computer Interface (BCI) technology. A qualitative, exploratory and descriptive study was carried out by means of interviews and analysis of textual content with mixed generation of categories and segmentation into frequency of topics. We present the results of three in-depth interviews that were conducted with Spanish speaking individuals who had previously completed a survey as part of a larger, 3-country/language, survey on BCI perceptions. 11 out of 15 of these Spanish respondents (survey) either strongly or somewhat accept the use of $\mathrm{BCI}$ in rehabilitation therapy. However, the results of our three in-depth interviews show how, due to a strong inertia of attitudes and perceptions about BCI technology, most professionals feel reluctant to use BCI technology in their daily practice (interview).
\end{abstract}

Keywords Brain-Computer Interfaces · Spanish rehabilitation professionals · Survey · Interview · Text mining · Qualitative study

Aníbal Monasterio Astobiza

amastobiza@ugr.es

David Rodriguez Arias-Vailhen

dra@ugr.es

Txetxu Ausín

txetxu.ausin@cchs.csic.es

Mario Toboso

mario.toboso@csic.es

Manuel Aparicio

manuel.aparicio@um.es

Daniel López

daniel.lopez@csic.es

1 Department of Philosophy I., University of Granada, Granada, Spain

2 Global Health and Social Medicine, Center for Bioethics, Harvard Medical School, Harvard University, Boston, USA

3 FiloLab-UGR, University of Granada, Granada, Spain

4 IFS-CSIC (Spanish National Research Council), Madrid, Spain

5 Department of Philosophy, University of Murcia, Murcia, Spain

\section{Introduction}

Understanding the usefulness new technologies have for society should begin with an understanding of stakeholders' views (e.g. manufacturers, health care professionals, patient advocates and government) on those technologies. Empirical studies (Comin et al. 2013) that study the adoption of technology link that acceptance and diffusion of technology with the characteristics of society (e.g. institutions, human capital, policies, adoption history, etc.)

In line with the research that analyzes the adoption and diffusion of technology in society we wanted to explore a little-studied aspect of neurotechnologies, and in particular Brain-Computer Interfaces (BCI). We believe there is a "knowledge gap": we know what researchers think (FECYT 2018), but we do not know exactly the attitudes of rehabilitation professionals about BCI technology. And this is a problem because (in the context of rehabilitation) it is the professionals who will end up recommending its use or not, who will assist the users in its use etc. When preparing the structure of our interviews, we have focused on three main themes of questions to ask professionals of rehabilitation: (a) BCI knowledge/experience, (b) follow up questions and 
(c) Technology impact on society. Many studies (Kaplan and Tripsas 2008) have shown the importance of these three axes in understanding the adoption, diffusion and change of technology.

$\mathrm{BCI}$ technology is intended to create a bridge between the brain and the outside world by coding neural outputs through an interface (Donoghue 2008; Musk and Neuralink 2019). It is usually intended to aid paralyzed humans in mobility and communication. BCI technology works by acquiring signals from brain waves, that are subsequently processed and interpreted by a machine or computer. BCI technology is mainly used as assistive technology to restore, increase, maintain, or improve functional capabilities of individuals with motor disorders or disabilities. But its market niche has grown in the recent years and applies beyond the therapeutic context in areas like the military and even consumer applications (e.g. entertainment).

BCI technology is the subject of much scientific and public attention (Grübler and Hildt 2014). It is consider the most promising technology for use beyond the therapeutic realm. Because it gives humans the ability to directly control external devices or machines - without the physical constraints of the body - a world of unpredictable future possibilities opens up. BCI technology has the potential to influence all facets of life. BCI technology is starting to be looked at from a military perspective because it can improve the performance of soldiers by improving their physical and cognitive power. Its medical benefits have already been discussed above, but for example people with amputated limbs can control external devices and through electrode implants patients with certain degenerative pathologies, such as Alzheimer's, can improve their memory. The potential use of technology in healthy people is enormous as well. Several technological companies (including Facebook or Neuralink) are investigating the potential use of BCI technology as an interface with their own social media platforms. The use of neurotechnologies such as BCIs generates social concerns about privacy. The location in direct contact with the brain and the recording and output functions of BCIs rises risks and multiple ethical questions, among them the protection of our most intimate information - brain data. BCIs are seen as technological devices that have the potential to "read minds" and "write minds". They "read" the mind because they measure and record neural activity that can decode mental states (Huth et al. 2016). And they can "write" the mind, because with implanted electrodes they can modulate neural activity (Lee et al. 2019). This in turn, raises questions about the authenticity of agency and even the autonomy of decision-making.

Our contribution relates to the use of BCIs in the context of clinical rehabilitation. It can be summarized as follows. First, the aim of this study was to explore the attitudes of professionals involved in rehabilitation regarding the use of BCI technology, its usefulness, and certain ethical and practical limits that the technology may have. To this end, we present the results of three in-depth interviews that were conducted with Spanish speaking individuals who had previously completed a survey as part of a larger, 3-country/language survey on BCI perceptions. So, in a sense this study is an extension of the study carried out with the survey. It is for this reason, because we relied in part on the previous survey study to create our qualitative three in-depth interview assessment study, that we have to mention part of the design used in that study. So, in several parts of the article, we will refer to the previous study as a way of understanding ours as a continuation and extension of it. As we have said above, in this study we want to discuss a topic that has been neglected in the research literature on BCI technology, say, the attitudes of rehabilitation professionals regarding the potential use of BCI technology in their daily practice.

\section{Background}

Scientific innovation is embedded in socioeconomic life and is fundamental to people's lives, policy and the technological capacity to exploit resources. Scientific communication between science and the research community, on the one hand, and the general public, on the other, has been categorized according to three basic models (Trench 2008): dissemination model, dialogue model and conversation model. The last model refers to the public understanding of science: a process that goes beyond the mere dissemination and transmission of knowledge to encompass a mutual learning between society and the scientific community that allows familiarity with a wide range of perspectives, frameworks and worldviews (Trench 2008). Recognizing the ethical, legal and social implications of the development of new technologies the very same scientists, but also all the stakeholders involved, must perform outreach activities and public participation in science. The public participation activities born out of a commitment to democratize science (Sclove 1995).

This model explains the perceptions and attitudes that the scientific community, the scientists themselves, have of citizens and society in general about science and vice versa. However, it does not especially emphasize the perceptions and attitudes that the practitioners (whether they are scientists or not) have of scientific innovation and technology in particular. The so called participation model of public communication of science and technology builds on social trust. Social trust can be seen as people's trust in science and technology policies. And to achieve this, this model is based on "public participation" and "public engagement" focusing on a number of activities to foster this social trust. Examples 
of these activities are public conferences, science festivals, science shops, citizen science programs.

This model of public participation that includes the opinion of practitioners whether they are researchers or not understands that science education is basic. In this sense, to know the degree of scientific and technological knowledge of all stakeholders, including the practitioners, is a must.

Hence the reason of this study: to know the perception and attitudes of Spanish rehabilitation professionals about BCI technologies. Our aim was to understand how professionals perceive BCI technology and how much do they accept to use it in their professional activity and practice. For this purpose, we developed a questionnaire and surveyed rehabilitation professionals, and conducted in depth interviews with a small sample.

\section{Methods}

This study is based on a historical tradition of using computers and other automated tools for social research on technology. A total of 15 individuals participated in the completion of the survey and 3 of them in interviews phase. Purposive sampling was used and recruitment was based on the participants' membership in Spanish professional associations (e.g. rehabilitation doctors, speech therapists, physical therapists). All participants agreed to complete the study. We used in depth-interviews with open-ended questions. The questions were based on the study by Sample et al. (2019), but this time they included questions that addressed the impact of the use of BCI technology on users, caregivers, children, people with disabilities, potential risks, and society at large. Participants were first provided with an overarching introduction about BCI technology and the purpose of the study. For example, we told them that although the application of BCI technology to rehabilitate functionality for people with some type of limited movement or neurodegenerative condition is what is usually emphasized, these are not the only possible applications. Brain-machine interfaces, also known as neural prostheses or neural interfaces, use neuronal information to control external devices such as wheelchairs or exoskeletons, but also home automation systems, computers, videogames and even military weapons. Participants were also told that they are used in research on stimulus communication between people (Ebrahim et al. 2017), human brain-to-brain communication through the internet (Rao et al. 2014) or communication from a human brain to a non-human one (Yoo et al. 2013). Participants were mentioned as well that BCI and other types of neurotechnology are also a theme within discourses on posthumanism and transhumanism which seek to overcome the limitations of the "normal" human condition (Kurzweill
2005). Participants were also informed of the components of a BCI basic setup. Instrumentally, the essential components of all neural interfaces are: (a) Sensors: they record the brain's electrical activity, which may be local activity of individual neurons or aggregated activity of hundreds, thousands or millions of neurons, (b) Decoder: a mathematical algorithm that processes, filters noise and amplifies the signal of the electrical activity recorded from the brain, converting it into a command signal to operate an effector or actuator. Decoding of the signal is crucial for effective functioning of the brain-machine interface, and (c) Effector o actuator: it may be a robotic arm, a prosthesis, the cursor of a computer, etc. The effector or actuator reflects the type of specific application of the brainmachine interface.

During the introduction to the technology, participants were told that the most basic classification that can be made on neural interfaces is based on their invasiveness: invasive or non-invasive. This distinction depends on whether the implants or electrodes (sensors) need to penetrate the integumentary system (skin). They can also be classified based on whether the interface is passive or active. In active BCI the user does mental work such as, for example, imagined movements that activate different parts of the motor cortex, which the interface system processes. Through active brainmachine interfaces it is possible to control a robotic arm to drink, walk with assistance from a robot or exoskeleton or drive a wheelchair. In passive BCI, the electrical activity from the brain is modulated in response to an external stimulus. Participants were exposed to questions categorized in: (a) BCI knowledge/experience questions, (b) followup/open-ended questions and (c) Technology and society questions.

Data analysis was carried out by coding the verbatim transcripts using qualitative software (Rockwell and Sinclair 2016). Each interview transcription was analyzed as whole. From theses transcriptions a set of themes were developed and 13 themes or categories were identified.

\subsection{Study design and sampling}

With a preliminary coding following ethical and social concerns raised in the relevant scientific literature (Sample et al. 2019; Burwell et al. 2017).

\subsection{Data analysis}

The interviews were recorded and transcribed as plain text. Then, a set of analytical tools for text analysis using computer-assisted interpretative practices were used (Rockwell and Sinclair 2016; Manning et al 2014). 


\subsubsection{A. Participants and study design}

Participants from Spain were recruited from a web based survey via Qualtrics (commercial survey software and web platform). The criteria recruitment for the participants was to be an active rehabilitation professional (member of a professional association: rehabilitation doctors, speech therapists or physical therapists). Spain is divided administratively and politically into autonomous communities or territorial entities and the specific rehabilitation association in each autonomous community was contacted (17 in total). The concrete example of the application of $\mathrm{BCI}$ technology was for the purpose of rehabilitation, restoration of a physical function, although other possible uses were also indicated like for example BCI technology as an augmentative tool or alternative communication access method. Participants voluntarily and anonymously agreed to participate in the study. A total of 15 people completed the survey as we stated above, but only three of them agreed to be interviewed later. So, the three professionals interviewed were among the 15 who carried out the survey. Two of the respondents to the interview were female (rehabilitation doctors) and the other a male (physical therapist). We do not looked at demographics to tell a possible correlation with the responses or see if the responses vary with demographic characteristics. As a qualitative study we were focused on the expressions and beliefs of the respondents.

\subsubsection{B. Ethics statement}

Participants gave their consent to the data protection measures which needs to comply with Art. 9 and 12 ff GDPR. The study was review and approved by the ethics committee of the University of Granada. The participants provided their written informed consent to participate in this study.

\subsubsection{Instrument}

Sample et al. (2019) shows more information on the preparation and validation of the items for the survey which received input and feedback from experts in fields such as neuroethics, medicine and engineering. See Table 1 for descriptive information on the instrument used. As a detailed analysis of the survey has already been described elsewhere (Sample et al. 2019), in this study we focus on the analysis of the interviews (transcribed into text) with text mining tools. Nonetheless, we will briefly explain below some aspects of the elaboration of the survey relevant to our own study. Some of the specific goals for the use of text mining or computer-assisted interpretative practices were to determine:

- What categories or topics occur throughout the interviews

- Whether there is an unexpected discovery of the texts that can be visualized

For this purpose, the choice of the right analytical tools was essential. We decided to use a free, open source text analysis software package, see Rockwell and Sinclair (2016) for further details, and the Stanford CoreNLP Natural Language Processing Toolkit which enables us to derive sentiment analysis (Manning et al. 2014).

Once the items of the survey were compiled according to the coding obtained, the participants were asked about their previous knowledge of the BCI technology before carrying out the survey. After obtaining the demographic data of the participants and their informed consent, they were given the 95 questions with an estimated average duration of $25 \mathrm{~min}$ to completion. See Sample et al. (2019) for further details on the survey. With the contact information of the participants in the survey who agreed to be interviewed later, we proceeded to conduct three in-depth interviews based on

Table 1 Source code guide

\begin{tabular}{|c|c|c|c|}
\hline Primary code & Secondary code & Definition & Source(s) \\
\hline \multirow[t]{2}{*}{ Psycho-social implications } & $\begin{array}{l}\text { Ethical conceptions of care for the } \\
\text { older, disabled people and children }\end{array}$ & $\begin{array}{l}\text { Concerns about how to guarantee the rights of chil- } \\
\text { dren, disabled people and the elderly in the light of } \\
\text { the development of technology and, specifically, } \\
\text { the challenge of addressing the care related needs } \\
\text { of these populations with BCI }\end{array}$ & Aparicio et al. (2020) \\
\hline & Inclusive and interactive robotics & $\begin{array}{l}\text { Robotics (including BCI technology) of the people, } \\
\text { for the people and by the people. Responsible } \\
\text { integration of robotics as a mediating factor in the } \\
\text { socializing process }\end{array}$ & Aparicio et al. (2020) \\
\hline Risk assessment & The RIHATRA risk assessment cycle & $\begin{array}{l}\text { The RIHATRA risk-assessment cycle going from } \\
\text { RIsk identification, who will be Harmed, Take } \\
\text { action, and Risk Assessment again of BCI technol- } \\
\text { ogy }\end{array}$ & Spiegelhelter (2017) \\
\hline
\end{tabular}


three types of questions: (a) questions about knowledge and experience on BCI technology, (b) open-ended questions and (c) questions about technology and society.

See Table 2 to see in detail the questions asked during the interviews. In the context of qualitative research, specifically qualitative research dealing with an analysis of speech and conversations, it is important to identify and differentiate categories and topics. Until the advent of automated analysis techniques thanks to the digital revolution of computers this was done manually by researchers. This was a challenge for the qualitative researchers and methodologists, because it involved a reading of the data that is within interpretivism or in other words always from the subjective perspective of the researcher. In this study, with automated methods we extracted themes from the respondent comments. The coming of age of DH (Digital Humanities) or more generally the application of mechanical coding methods (tools to extract topics in the respondent comments) assumed a change of direction beyond interpretivism benefitting scholarship. And this is what we have done. We came to this study the way many researchers come to use different approaches to their data: with the conviction that traditional methods often do not work and the toolkit need to be expanded.

\section{Results}

$76 \%$ of Spanish respondents (survey) either strongly or somewhat accept the use of Brain-Computer Interfaces (BCI). However, the in-depth interview showed other nuances. Three in-depth interviews analyzed showed a strong willingness on the part of the interviewees not to use technology in their daily practice. This makes us hypothesize that the beliefs and attitudes of Spanish rehabilitation professionals are a non-technological barrier to the implementation of BCI technology. Next, we present text analysis using computer-assisted interpretative practices applied to the transcribed interviews.

In Fig. 1, we show 13 categories or topics and their relative frequency in texts (transcribed interviews). The selection of the categories is based on the coding established in Table 1 (e.g. psycho-social, inclusiveness and risk). These 13 categories are: 1- "technology", 2- "brain", 3- "interfaces", 4- "computer", 5- "technologies", 6- "persons", 7- "professionals", 8- "decisions", 9- "rehabilitation", 10- "experience" and 11- "ethics", 12-"development" and 13- "question" (Note that the categories or topics appear in Spanish in all the graphs since the interviews were made in Spanish. To understand what every term corresponds to we use a numerical pairing, one for the Spanish translation of categories and one for the English translation. The categories in Spanish are 1- "tecnología", 2- "cerebro", 3- "interfaces", 4- "ordenador", 5- "tecnologías", 6- "personas", 7- "profesionales",

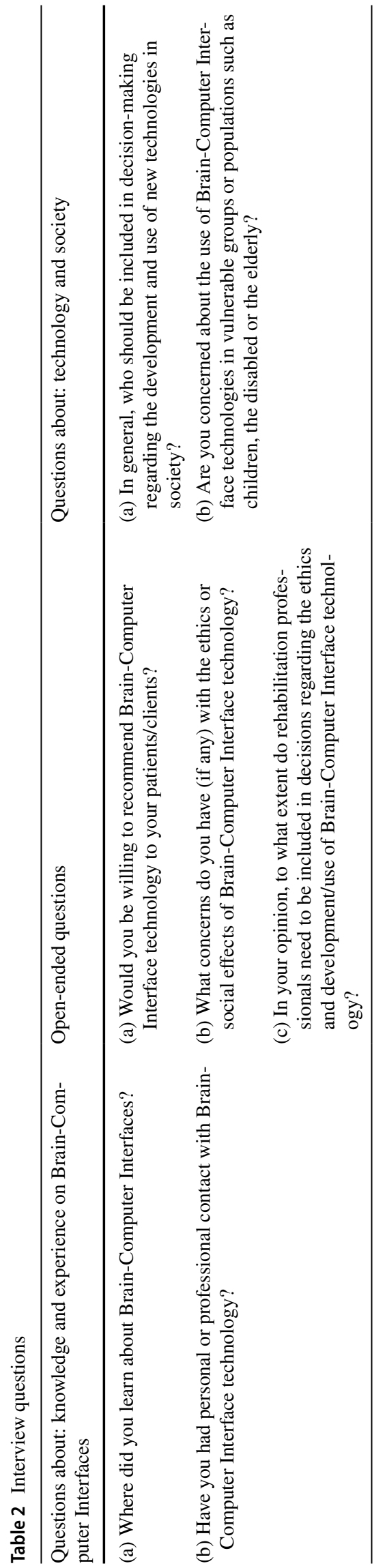




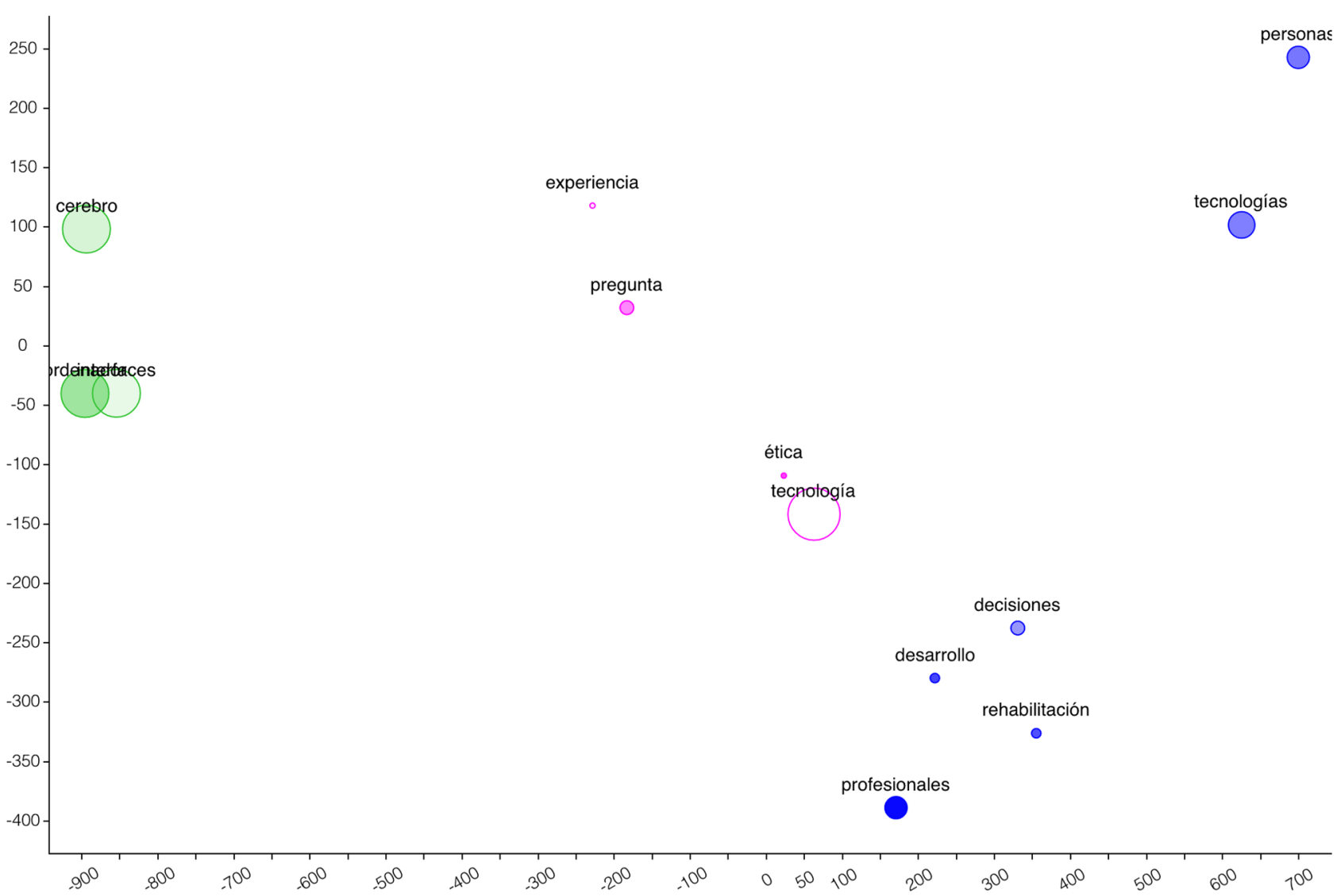

Fig. 1 Scatterplot visualizing the relative frequency of 13 categories or topics. Each colored circle represents a category or topic and the size of the circle the correspondence of word use in the corpus (interview). The visualization relies on a statistical analysis that takes the word 's correspondence from the corpus showing absolute and relative frequency in three dimensions (Axis $\mathrm{X}$, Axis $\mathrm{Y}$ and a third axis corresponding to the area of each circle. It provides a Cartesian ( $\mathrm{x}$, y) point for each term based on word frequency across the transcripts of the interviews. Principal Component Analysis makes a coordinate axis of the frequency of certain categories in a textual corpus. It analyses how each category is associated with another, the direction of

8- "decisiones", 9- "rehabilitación”, 10- “experiencia", 11"ética", 12-"desarrollo" and 13- "pregunta"). In the scatter plot graph, the technique used was Principal Component Analysis (PCA). This technique takes data (transcribed text) in a multidimensional space and optimizes it, reducing all the dimensions to a more tractable subset. PCA works by transforming the data to its own internal structure, so the association between the data points becomes more apparent.

For example, consider the relative frequency of categories or topics in our three transcribed texts. The transcribed text can be thought of as a multidimensional space, and each word frequency as a data point. Since we cannot visualize a multidimensional space, we can apply PCA to reduce the number of dimensions to something more handy such as two or three. This is achieved by transforming the data into a new dispersion and the value of these directions (which can be negative or positive). All this on four axes represented in $2 \mathrm{D}$, which is why one appears in positive and the other in negative. Regarding the visualization of two categories, 3- "interfaces" and 4- "computer", both appear at the same coordinate, which implies that they overlap in the display. (Note that the categories or topics appear in Spanish in all the graphs since the interviews were made in Spanish. However, see later in text, to understand what every term corresponds to we add a number to both English and Spanish categories. There is a small defect in the display of the item "personas" where the last letter of the word is cut off)

space where a few dimensions (components) represent the enormous variability in the data.

In Fig. 2, we show the very same 13 categories described above and their change in relative frequency in a more aesthetically appealing visualization. Stream graph is used to automatically segment a text (transcribed interview) into topics or categories.

Below is a selection of excerpts from each of the interviews. We have selected these fragments because they are representative of the social concerns that the participants showed about the possible use of BCI technology. On the other hand, to a certain extent they also reflect some categories, for example "ethics", that have appeared in the three interviews in a combined way.

Example 1: excerpt from one interview. 


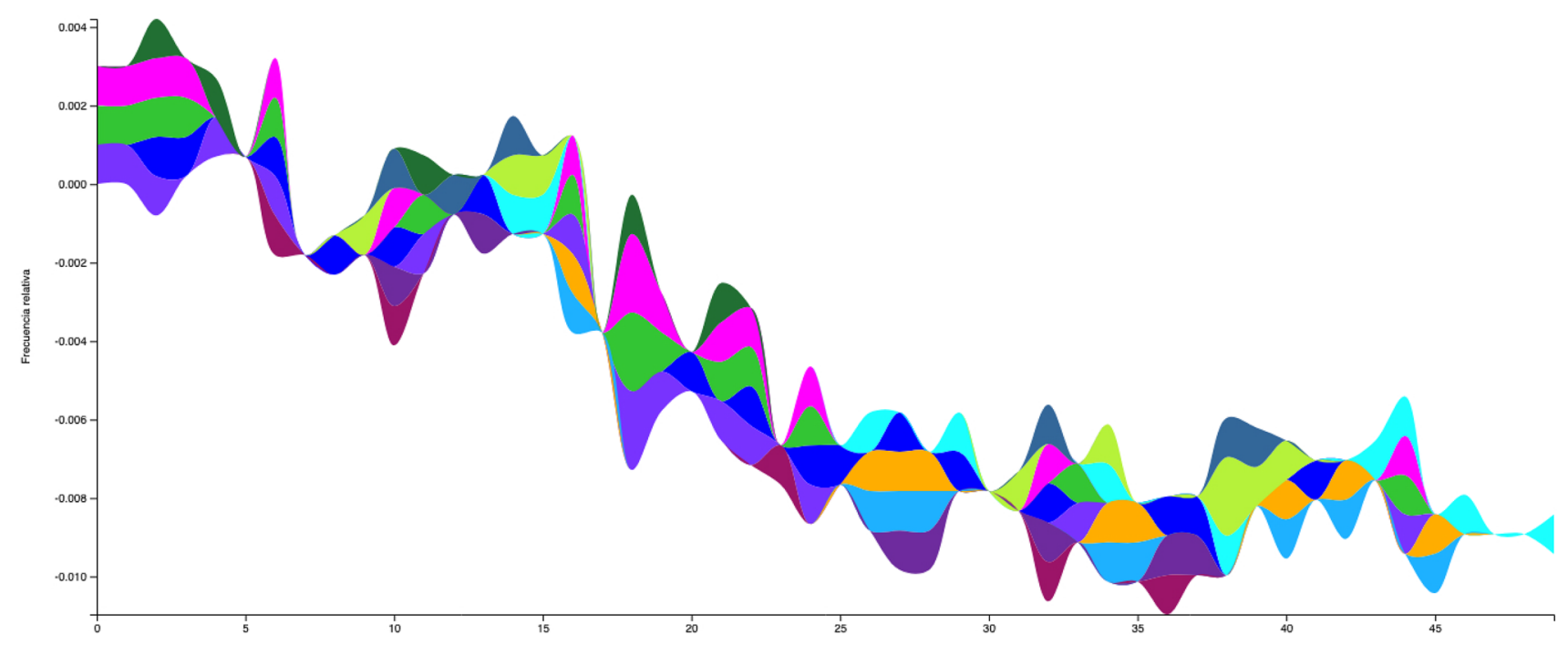

Fig. 2 Stream graph depicts the relative frequency and segmentation of 13 categories. Each colored line represents a category or topic: dark green $=$ technology; pink $=$ brain; purple $=$ interfaces; blue $=$ computer; light blue $=$ technologies; dark blue = persons; light green $=$ professionals; lighter green $=$ question; dark purple $=$ decisions; darker purple $=$ development; orange $=$ rehabilitation; dark

"At the moment I do not recommend it due to my lack of experience in this field and because they are in a development phase, apart from the technical and economic difficulty of acquisition by the patient"

Example 2: excerpt from one interview.

"The concern is that such patient information and his or her data may be used for economic benefit by corporations"

Example 3: excerpt from one interview.

"Another concern is the monopoly of this type of technology for the benefit of a few, as well as the depersonalization of medical care"

Example 4: excerpt from one interview.

"I suppose this is partly due to my lack of knowledge about this technology, but there may be a debate in society about whether people who use these technologies are really going to use them in complete freedom, or whether the technology itself may lead them, without them realising it, towards certain decisions."

Example 5: excerpt from one interview.

"In my opinion, all of us living in the West are continually being influenced in our decisions, opinions, thoughts... and what is more, with these technologies red=experience and light red=ethics. The bottom $X$ axis corresponds to segments of the corpus (interviews) and Axis Y corresponds to the relative frequency of the categories. (Note that the categories or topics appear in Spanish in all the graphs since the interviews were made in Spanish) (color figure online)

it is even possible that all these biases can be avoided if this technology is developed to do so".

Example 6: excerpt from one interview.

"I believe that they should be included because we are the professionals who work to improve the participation and social inclusion of people who are subsidised by these technologies."

Excerpt 1 reflects the lack of acquaintance with technology and the belief that because it is in a developmental phase, its use would not be recommended. Another interviewee, Excerpt 3, considers the risk of monopoly of this technology in the hands of the few and that it could lead to the depersonalization of medical care. In Excerpt 2, the main worry is privacy and how patient data can be exploited with malicious interests. Excerpt 4, as in Excerpt 1, reflects a constant pattern found in all in-depth interviews: lack of knowledge or familiarity with the BCI technology. Excerpt 5 indicates a reasonable scepticism about the malicious use of technology for manipulation. Finally, Excerpt 6 shows the need to take rehabilitation professionals into account when implementing and making this technology more accessible to people.

Quantitative analysis of the responses revealed percentage of total words within the text and includes an emotional tone -positive or negative emotion dimensions. Overall, the 
answers to the interview questions had a negative emotional tone.

\section{General discussion}

Text mining and analysis using computer-assisted interpretative practices (Monasterio 2018) decontextualized and quantified the relative frequency of certain components (e.g. words, topics or categories) which is extremely effective for a qualitative study like the one we have done. The use of these tools has allow us to "see through text". This facilitates a process that Franco Moretti called "distant reading" (Moretti 2013): a process that allows you to focus on small units, such as words, or things larger than the text itself (e.g. an author's entire work). In our case, we wanted to find a recurrence of topics or categories in the transcribed text that would reflect our codification on the basis of three themes related to BCI technology. These three themes are: psychosocial implications, inclusiveness or interactiveness, and risk of BCI technology. These three themes are present in the words used in the speeches of three in-depth interviews transcribed in text and analyzed with text mining tools. The results of the study provide important insights about the perception and attitudes of Spanish rehabilitation professionals towards BCI technology.

$\mathrm{BCI}$ technology raises important ethical questions that have been much discussed by ethicists and practitioners. Assessing the categories and themes found during the interviews so far, rehab professionals regard the potential of BCI technology very highly, but at the same time they acknowledge their lack of familiarity with the technology. They also express their social and cultural concerns about the malicious use of BCI technology with the aim of manipulating or transforming people. The construction of the image of technology, and in particular BCI technology, in the popular imagination follows a mainly apocalyptic narrative. Many people see the possibility to engage with technology, or even the "cyborgization" of the human body, as a threat rather than an opportunity. In BCI technology, brain sciences and computer science, especially Artificial Intelligence with predictive algorithms, come together. Public perception and understanding of brain sciences and AI is marked by mostly a negative characterisation. In relation to brain sciences many people react negatively to the possibility of manipulating thoughts and agency with advances and developments in neuroscience. On top of that, the development of neurotechnology capable of being in direct contact with the brain, causes fear in the people who want to preserve the integrity of their consciousness and thought processes. In fact, the possibility of neurorights or guarantees of protection of personal identity understood as non-interference in the form of intervention, manipulation etc. of the brain, are already being called for by researchers and legislative initiatives are being put in place (Bublitz and Merkel 2014; Ienca and Andorno 2017; Montes 2020). In this sense, BCI technology must be promoted in a realistic way, allowing its desirable and valuable qualities to be known.

On the other hand, traditional "close reading" of the transcribed text has allowed us to observe some nuances. Despite the fact that the vast majority of those interviewed and those who carried out the survey accept positively the use of BCI technology, very few would use it in their daily practice.

(See Example 1: excerpt from one interview). How can this be? We speculate that perceptions and attitudes towards technology act as non-technological barriers with greater inertia than other types of incentives.

Barriers in the mind of professionals who could use the BCI technology are often more pervasive than technical barriers. It is true that the technical dimension could be a mind barrier in itself as pointed out by an anonymous reviewer. But we have in mind an analytical distinction between nontechnological barriers and technical barriers. Traditionally, non-technological barriers are grouped into three categories: (a) economic or trade barriers, (b) regulatory barriers, and (c) stakeholder's perceptions and attitudes towards a given technology. As we observed after the analysis of the interviews, the main barrier for the Spanish professionals belonged to the category of perceptions and attitudes. Perception and attitudes, especially if they are negative, are a very common impediment for technological adoption.

For the sake of our objective, to asses - from a qualitative perspective- the perceptions and attitudes of Spanish rehabilitation professionals (e.g. rehabilitation doctors, speech therapists, physical therapists), discourse analysis is used to focus in how participants use language to describe BCI technology. From the perspective of Science and Technology Studies (STS), we stress that the practical, representational and axiological dimensions of the discourses of each community are relevant when studying the social appropriation of technologies in their own practical environments.

A community's approach approach and relationship to a certain technology can be viewed as mediated and signified by means of intertwining sets of values, representations and social practices in regard to it (Lynch 1988). This way of understanding the relationship allows us to talk about the community's “discourse" (Mahoney and Goertz 2006) about BCI technology. We note that in experimental application of BCI technology characteristics such as rehabilitation, noninvasiveness, security and applicability emerge as relevant values for this technology.

On the other hand, the perception of risk by a community of experts or practitioners depends on several factors studied by psychologists. For example, the essential characteristics of risk for Slovic (1987), taking into account his studies with 
experts and non-experts, are: uncontrollability, catastrophic potential, fatal consequences and inequitable distribution of costs and benefits.

To mitigate these negative perceptions and attitudes towards BCI technology, their potential should be realistically described and their benefits and risks defined, and strategies for the prevention and mitigation of such risks should be sought. As main non-technological barriers, together with perceptions and attitudes, we consider that the lack of knowledge and experience with BCI technology prevents its progressive diffusion and adoption. Robust and effective ethics by design could contribute to improve trust in this technology which is a precondition for its acceptance and adoption. As mentioned by an anonymous reviewer, it is true that a more critical position can also be encouraged in the same way and instead of incentivize trust why not social, cultural or even philosophical criticism to the technology (Coeckelbergh 2020).

In qualitative research there is no 'optimal' number of interviews (Hammarberg et al. 2016; Morse 2000; Sandelowski 1996; Marshall 1996; Patton 1990), what matters is the quality of the data, not the number of interviews, so no equivalent exists of a sample size as in quantitative research. There can be some value in qualitative research with as little as one interview (purposive sampling instead of probability sampling as done in quantitative research). So we decide to go ahead with only three in-depth interview for text analysis using computer-assisted tools. But qualitative methodology relying on the notion of thematic saturation considers that 6-12 interviews is the minimum (See, Fusch and Ness 2015). Nevertheless, with purposive sampling procedure its aim is to select information in rich cases "whose study will illuminate the questions under study" (Patton 1990, p. 169). A previous study analyzed the surveys (Sample et al. 2019), whose questions consisted of finding out what people know about BCI technology and its social, legal and ethical implications. In this qualitative study, we want to find out which topics or categories are recurrent in the conversation with different Spanish rehabilitation professionals and whether the topics correspond to the coding guide previously established.

\section{Conclusion}

According to our survey a majority of rehab professionals either strongly or somewhat accept the use of Brain-Computer Interfaces (BCI) in rehabilitation therapy. However, our qualitative study based on three in-depth interviews with professionals shows strong societal (and other concerns), attitudes and perceptions, against BCI technology use in their daily practice (interview). We conclude that non-technological barriers based on preferences, attitudes and perceptions regarding BCI technology are not easy to change and that we need more work in this area to see which factors influence their formation. However, we believe that educational programs that publicize the technology and its potential benefits could be a good strategy to reduce the lack of knowledge about BCI technology. Practitioners and other rehab professionals are qualified people, but as they themselves have expressed in the interviews we have conducted with them, they need more familiarity with BCI technology. We believe that a closer approach to this technology is necessary. In order for rehab professionals to use BCI technology, it needs to be integrated in their daily practice. They need to see the connections to what they do and BCI technology must help them to achieve their goals.

Acknowledgements The authors gratefully acknowledge the support of the following research projects: Intelligent Neuro-Technologies Restoring Functions of Action and Communication: An Evaluation Study (Interfaces) AC15/00085 (FEDER), EXTEND (H2020 Research Project, ref. 779982) and EthAI+3 (PID2019-104943RB-100). Aníbal Monasterio Astobiza and David Rodriguez Arias-Vailhen would like to thank Matthew Sample for his help in carrying out this study. Aníbal Monasterio Astobiza would also like to thank Jordi López-Sintas for his advice on qualitative analysis.

Funding Funding for open access charge: Universidad de Granada / CBUA. Intelligent Neuro-Technologies Restoring Functions of Action and Communication: An Evaluation Study (Interfaces) AC15/00085 (FEDER), EXTEND (H2020 Research Project, ref. 779982) and EthAI + 3 (PID2019-104943RB-100).

Data availability All data generated or analyzed during this study are included in this published article.

\section{Declarations}

Conflict of interest The authors declare no conflict of interest.

Open Access This article is licensed under a Creative Commons Attribution 4.0 International License, which permits use, sharing, adaptation, distribution and reproduction in any medium or format, as long as you give appropriate credit to the original author(s) and the source, provide a link to the Creative Commons licence, and indicate if changes were made. The images or other third party material in this article are included in the article's Creative Commons licence, unless indicated otherwise in a credit line to the material. If material is not included in the article's Creative Commons licence and your intended use is not permitted by statutory regulation or exceeds the permitted use, you will need to obtain permission directly from the copyright holder. To view a copy of this licence, visit http://creativecommons.org/licenses/by/4.0/.

\section{References}

Aparicio M, Toboso M, Ausín T, López D, Morte R, Monasterio A (2020) Discursive frameworks for the development of inclusive robotics. In: Pons J (ed) Inclusive robotics for a better society. INBOTS 2018. Biosystems and biorobotics, vol 25. Springer, Cham 
Bublitz JC, Merkel R (2014) Crimes against minds: on mental manipulations, harms and a human right to mental self-determination. Crim Law Philos 8:51-77

Burwell S, Sample M, Racine S (2017) Ethical aspects of brain computer interfaces: a scoping review. BMC Med Ethics 8(1):60

Coeckelbergh M (2020) Introduction to philosophy of technology. Oxford University Press, Oxford

Comin D et al (2013) The spatial diffusion of technology" NBER Working Paper No. w18534. Available at SSRN: https://ssrn.com/ abstract $=2178293$. Accessed 21 Sept 2020

Donoghue JP (2008) Bridging the brain to the world: a perspective on neural interface systems. Neuron 60(3):511-521

Ebrahim M et al (2017) Human-to-human closed-loop control based on brain-to-brain interface and muscle-to-muscle interface. Sci Rep 7:11001

Fundación Española para la Ciencia y la Tecnología (FECYT). Percepción social de la ciencia y la tecnología 2018 [Online]. Available: https://icono.fecyt.es/informes-y-publicaciones/percepcionsocial-de-la-ciencia-y-la-tecnologia-en-espana. Accessed on 15 Dec 2020

Fusch PI, Ness LR (2015) Are we there yet? Data saturation in qualitative research. Qualitat Rep 20(9):1408-2141

Grübler G, Hildt E (2014) Brain-computer-interfaces in their ethical social and cultural contexts. . Springer, Heidelberg

Hammarberg K et al (2016) Qualitative research methods: when to use them and how to judge them. Hum Reprod 31(3):498-501

Huth A et al (2016) Decoding the semantic content of natural movies from human brain activity. Front Syst Neurosci. https://doi.org/ 10.3389/fnsys.2016.00081

Ienca M, Andorno R (2017) Towards new human rights in the age of neuroscience and neurotechnology. Life Sci Soc Policy 13(1):5

Kaplan S, Tripsas M (2008) Thinking about technology: applying a cognitive lens to technical change. Res Policy 37:790-805

Kurzweill R (2005) The singularity is near: when humans transcend biology. Viking, New York

Lee $\mathrm{M}$ et al (2019) Brain-computer interfaces in quadriplegic patients. Neurosurg Clin N Am 2:275-328

Lynch M (1988) Sacrifice and the transformation of the animal body into a scientific object: laboratory culture and ritual practice in the neurosciences. Soc Stud Sci 18:265-289

Mahoney J, Goertz G (2006) A tale of two cultures: contrasting quantitative and qualitative research. Polit Anal 14:227-249

Manning C et al (2014) The Stanford CoreNLP Natural Language Processing Toolkit Proceedings of the 52nd Annual Meeting of the Association for Computational Linguistics: System Demonstrations, $\mathrm{p}$ 55-60
Marshall MN (1996) Sampling for qualitative research. Fam Pract 13(6):522-526

Monasterio AA (2018) Repensando la estructura conceptual del contínuum filosofía-psicología: Uso de big data y minería de datos para analizar la transformación conceptual de la filosofía y la psicología. Caracteres: Estudios Culturales y Críticos de la Esfera Digital 7, 1, 126-155

Montes R (2020) Chile, laboratorio mundial de los neuroderechos [Online]. Available: https://elpais.com/ciencia/2020-10-08/chilelaboratorio-mundial-de-los-neuroderechos.html. Accessed on 11 Aug 2021

Moretti F (2013) Distant reading. Verso, London

Morse JM (2000) Determining sample size. Qual Health Res 10(1):3-5

Musk E, Neuralink (2019) An integrated brain machine interface platform with thousands of channels. J Med Internet Res. https://doi. org/10.2196/16194

Patton MQ (1990) Qualitative evaluation and research methods (2nd ed.) Sage Publications, Inc

Rao R et al (2014) A direct brain-to-brain interface in humans. PLoS ONE. https://doi.org/10.1371/journal.pone.0111332

Rockwell G, Sinclair S (2016) Hermeneutica: Computer-Assisted interpretation in the humanities. MIT Press, Cambridge MA

Sample M et al (2019) Do publics share experts' concerns about BrainComputer Interfaces? A trinational survey on the ethics of neural technology. Sci Technol Hum Values. https://doi.org/10.1177/ 0162243919879220

Sandelowski M (1996) One is the liveliest number: the case orientation of qualitative research. Res Nurs Health 19(6):525-529

Sclove R (1995) Democracy and technology. Guilford, New York

Slovic P (1987) Perception of risk. Science 236:280-285

Spiegelhelter D (2017) Risk and uncertainty communication. Annu Rev Stat Appl 4(1):31-60

Trench B (2008) Towards an analytical framework of science communication models. In: Cheng D, Claessens M, Gascoigne NRJ, Metcalfe J, Schiele B, Shi S (eds) Communicating science in social contexts: new models, new practices. Springer, Dordrecht, pp 119-135

Yoo S et al (2013) Non-invasive brain-to-brain interface (BBI): establishing functional links between two brains. PLoS ONE. https:// doi.org/10.1371/journal.pone.0060410

Publisher's Note Springer Nature remains neutral with regard to jurisdictional claims in published maps and institutional affiliations. 